\title{
Comunidade e reconhecimento nas relações econômicas
}

\author{
Luis Guilherme Galeão-Silva, ${ }^{\mathrm{I}, 1}$ \\ Lauro Gonzalez ${ }^{\mathrm{II}, 2}$ e Mario Aquino Alves ${ }^{\mathrm{II}, 3}$ \\ ${ }^{I}$ Instituto de Psicologia da Universidade de São Paulo (São Paulo, SP) \\ II Escola de Administração de Empresas de São Paulo da Fundação Getulio Vargas (São Paulo, SP)
}

\begin{abstract}
A redução da pobreza exige esforços sociais em vários campos, e entre eles estão aqueles que se referem a políticas públicas, geração de renda e mobilização de (recursos) sociais. A construção de diagnósticos e intervenções para a redução da pobreza exige, também, a colaboração de diferentes saberes sobre a sociedade, em especial gestão pública, psicologia social e finanças. A pesquisa aqui apresentada tem como objetivo investigar a contribuição da comunidade em seus aspetos sociais, organizativos e econômicos, para viabilização e impacto de programas de microcrédito produtivo, com atenção específica aos impactos relativos a redução da pobreza e inclusão social. Foram realizados grupos de discussão, entrevistas fechadas e entrevistas semidirigidas a mulheres moradoras de uma favela na cidade de São Paulo. Os resultados indicam que, para utilizar o microcrédito produtivo, é possível considerar o capital social como garantia, mas a capacidade de sua utilização pelas pessoas envolve complexas mediações entre o capital, a fragilidade relacional e a luta por reconhecimento.
\end{abstract}

Palavras Chave: Psicologia social comunitária, Interdisciplinar, Capital social, Reconhecimento, Economia.

Community and recognition in economic relations

Poverty reduction requires social efforts in several fields, such as those related to public policies, income generation and mobilization of social resources. Building diagnostics and interventions aiming at poverty reduction also requires the collaboration of different knowledge on society, particularly on public administration, social psychology and finances. This research aims at investigating how the community contributes in its social, organizational and economical aspects for making feasible and impacting productive microcredit programs, with particular attention to consequences related to poverty reduction and social inclusion. Discussion groups, closed and semi-structured interviews were conducted with women living in a slum in Sao Paulo. Results indicate that, in order to use a productive microcredit, it is possible to consider the social capital as guarantee, but the ability to use it involves complex mediations between capital, relational fragility and struggle for recognition.

Keywords: Community social psychology, Interdisciplinary, Social capital, Recognition, Economy.

\section{Introdução}

\begin{abstract}
A redução da pobreza exige esforços sociais em vários campos, e entre eles estão aqueles - que se referem a políticas públicas, geração de renda e mobilização de (recursos) sociais. A construção de diagnósticos e intervenções para a redução da pobreza exige, também, a colaboração de diferentes saberes sobre a sociedade, em particular gestão pública, psicologia social e finanças. A pesquisa aqui apresentada tem como objetivo investigar a contribuição da comunidade em seus aspetos sociais, organizativos e econômicos, para viabilização e impulso de programas de microcrédito produtivo, com atenção específica aos impactos relativos a redução da pobreza e inclusão social.
\end{abstract}

1 Professor de Psicologia Social do Instituto de Psicologia da Universidade de São Paulo. Departamento de Psicologia Social e do Trabalho.

2 Professor da Escola de Administração de Empresas de São Paulo da Fundação Getulio Vargas. Departamento de Contabilidade, Finanças e Controle.

3 Professor da Escola de Administração de Empresas de São Paulo da Fundação Getulio Vargas. Departamento de Gestão Pública. 
A área abrangida pelo projeto é a favela Nova Jaguaré, na cidade de São Paulo, sobre a qual expõe a Prefeitura de São Paulo:

A Favela Nova Jaguaré é a maior em construção contínua da cidade, onde 12 mil pessoas vivem em quatro mil domicílios... Localizada na região oeste do município, entre as ruas Barão de Antonina e Catalunha, entre as pontes da Fepasa e Jaguaré, a área da favela tem $168.000 \mathrm{~m}^{2} \mathrm{e}$ vem em processo de ocupação desde 1960. Em 1980, parte do local recebeu redes de abastecimento de água e energia elétrica (Prefeitura Municipal de São Paulo, 2008).

Nesta área, a prefeitura mantinha uma política pública de proteção social em parceria com uma instituição local, a Congregação Santa Cruz: trata-se do Programa Ação Família (SMADS, 2006), criado em 2005. A partir de 2009, a denominação do programa mudou, passando a se chamar Programa de Atenção Integrada à Família (PAIF), que é o termo atualmente utilizado por este tipo de programa no Sistema Único de Assistência Social (SUAS). Para que a pesquisa se viabilizasse, houve um acordo entre o PAIF e a Congregação Santa Cruz, de modo que o conteúdo empírico da pesquisa tem como foco, como se verá adiante, um conjunto de pessoas e famílias da comunidade assistidas pelo referido programa. $\mathrm{O}$ PAIF foi encerrado na região em 2010.

O PAIF era regionalizado, ou seja, para cada região de maior concentração de pessoas com alta vulnerabilidade, a prefeitura designava uma ONG ou entidade da sociedade civil que se encarregasse de gerenciar a ação social conveniente para a região sob sua responsabilidade. Em consequência, o número de membros de cada equipe era proporcional ao número de famílias assistidas, contando sempre, cada uma, com a participação necessária de um gerente ou um técnico (psicólogo, assistente social, terapeuta ocupacional etc.). Cada técnico era responsável por, no máximo, quatrocentas famílias. Moradores da própria comunidade, recrutados para integrar as equipes, faziam o acompanhamento das famílias, e cada um era responsável por, no máximo, 150 famílias assistidas pelo programa: eram os chamados Agentes de Proteção Social (APS).

O programa visava a melhorar três dimensões da vida das pessoas atingidas: vida em família, vida em comunidade e vida de direitos e deveres. As famílias eram acompanhadas por APS em visitas domiciliares e em grupos socioeducativos conduzidos por um dos técnicos do PAIF.

Para controle e definição da população assistida pelo PAIF, o Índice Paulista de Vulnerabilidade Social foi encomendado pela Assembleia Legislativa do Estado de São Paulo à Fundação Seade. Era um conjunto de indicadores que expressavam o grau de desenvolvimento social e econômico dos 645 municípios do estado (SEADE, 2008). Este índice abrangia duas dimensões: a econômica e a demográfica. As dimensões econômica (renda e situação de trabalho) e demográfica (número de membros e sua idade) são utilizadas para definir os níveis de vulnerabilidade para áreas geográficas com, aproximadamente, trezentas famílias (SEADE, 2008).

A fim de investigar o acima mencionado, tratar-se-á, a seguir, do referencial teórico relevante, incluindo o conceito de capital social e microcrédito. Na sequência, serão discutidos os aspectos metodológicos e o desenvolvimento do questionário aplicado na comunidade, assim como será feita uma análise empírica dos questionários e dos grupos de discussão conduzidos, com ênfase nas questões relativas aos arranjos de microcrédito. Serão, então, apresentados os comentários finais e as possíveis linhas de continuidade de estudo. 


\section{Referencial teórico}

O referencial teórico está dividido em três temas. O primeiro deles relaciona-se à subjetividade das pessoas atendidas por programas de proteção social, que é a condição de marginalizado(a) da sociedade. O segundo é o papel do crédito como elemento produtivo e as dificuldades de torná-lo efetivo na vida dos pobres. Por fim, são apresentadas as categorias de recursos que foram observadas na população, além do capital econômico (capital social, solidariedade).

\section{Exclusão social, motivação e cidadania}

Não é de surpreender que a condição de marginalizado deixe profundas marcas na subjetividade. A subjetividade é uma possibilidade social com precondições orgânicas (Horkheimer \& Adorno, 1978). Existe uma ameaça social evidente pairando sobre os marginalizados da sociedade - negros, mulheres, pobres, deficientes etc. -, que diz respeito tanto às precondições orgânicas (risco à sobrevivência pela fome, pelas doenças ou pelo frio) quanto a vários aspectos da subjetividade (como o respeito, a realização pessoal e a felicidade). Em decorrência, pode-se facilmente concluir que a ameaça à existência do marginalizado e de sua família causa terríveis consequências.

Essas considerações sobre a ameaça aos marginalizados devem ter, porém, uma ressalva: não existe, em si, uma subjetividade peculiar do marginalizado, nem qualquer déficit ou deficiência a ela equivalente. $O$ que se manifesta em sua condição é, exatamente, a própria condição humana, em toda sua precariedade. Os outros, aqueles que não são marginalizados, pois pertencem a outras classes sociais ou grupos sociais dominantes, compartilham da mesma condição, mas se esforçam para se iludir quanto à segurança de que pensam desfrutar ao viver em uma sociedade desigual. Além disso, alimentam a ilusão de que não estão no nível daqueles de condição humana precária e sustentam esse engano desenvolvendo sentimentos antagônicos em relação aos evidentemente precários, seja sob a forma de um animus magnânimo, seja por um violento desprezo.

A subjetividade das pessoas marginalizadas, em suma, é afetada por mecanismos sociais que prejudicam a experiência. Sucintamente, apresentaremos esses efeitos na compreensão da ameaça de o marginalizado passar da vulnerabilidade para a desfiliação e o sentimento do sofrimento social, para concluir que, além da ausência de condições objetivas, existem condições subjetivas que reproduzem a condição da marginalidade de renda.

A desfiliação social (Castel, 1997) é uma ameaça para muitas famílias. Há duas dimensões de filiação social: a primeira é o trabalho, pois este é a grande fonte de renda para a subsistência da família; a segunda é a inserção relacional na sociedade. Na primeira dimensão, as pessoas podem estar em três graus, da integração à ruptura: o trabalho estável, o trabalho precário e o não trabalho. Os estágios da segunda dimensão são: inserção relacional forte, fragilidade relacional e isolamento relacional.

Acoplando estas gradações duas a duas, obtêm-se três zonas, ou seja, a zona de integração (trabalho estável e forte inserção relacional, que sempre estão juntos), a zona de vulnerabilidade (trabalho precário e fragilidade dos apoios relacionais) e a zona de marginalidade, que se prefere chamar de zona de desfiliação, para marcar nitidamente a amplitude do duplo processo de desligamento: ausência de trabalho e isolamento relacional. (...) o tratamento dispensado à indigência inválida define uma quarta zona, a zona da assistência. Essa última realiza uma proteção aproximada, fundada no princípio da 'casa de caridade' (Castel, 1997, pp. 23-24, grifos no original). 
Sentimentos causados pela marginalização são, ao mesmo tempo, subjetivos e sociais, ou seja, não são somente idiossincrasias individuais. Um sentimento é uma expressão da experiência da pessoa. Além disso, o sentimento de marginalização é mediado por um estigma.

Além da teoria de Castel sobre a marginalização, considera-se crucial a forma como as pessoas podem aproveitar recursos de crédito de forma produtiva para a comunidade e para elas mesmas. Essa possibilidade está relacionada a sua vulnerabilidade; não é consequência apenas da pobreza, mas também da omissão de direitos (Kowarik, 2009). Esse aspecto da vulnerabilidade política, além da econômica, significa que a dificuldade no acesso a direitos fundamentais, como moradia, saúde, habitação e alimentação, representa um risco às famílias que foram pesquisadas.

Nesta altura, é válido lembrar a teoria de Honneth (2003) sobre a luta por reconhecimento, na qual o autor procurou uma concepção dialética para explicar a luta por reconhecimento como efeito dos conflitos sociais, em que prevalece a dicotomia entre dominante e dominado. Esses conflitos podem ser analisados como seguindo uma determinada gramática, ou seja, como ações comunicativas impregnadas de posições de poder e de normas sociais, que apresentam uma oposição, uma luta por respeito versus desrespeito. Para Honneth, as três dimensões do reconhecimento recíproco são: amor, direitos e solidariedade, que são as etapas de formação e mudança das normas sociais. Em cada dimensão do reconhecimento, há uma oposição entre respeito e desrespeito. Ao amor, opõe-se a violação do corpo; aos direitos, a violação de normas jurídicas; e à solidariedade, a degradação e a ofensa (Honneth, 2003). Em cada uma dessas dimensões, ocorre a necessidade do reconhecimento recíproco, ou seja, não é possível apenas uma pessoa ou grupo ser respeitado; é necessário um respeito generalizado. Tem-se, então, uma chave interpretativa dos conflitos sociais e das demandas por reconhecimento. Nas três dimensões, existem conflitos que cognitiva e afetivamente ameaçam o respeito aos sujeitos envolvidos - a violação do corpo, dos direitos, a degradação e a ofensa. Também há conflitos em que há a expectativa de ao menos um dos envolvidos receber respeito - o amor, o direito e a solidariedade. Estes seriam os movimentos que permitem se passar da competição entre dominante e dominado para a cooperação solidária.

\section{O microcrédito}

A fim de examinar as estratégias e os arranjos de microcrédito mais adequados à realidade da Comunidade Jaguaré, é importante que se adote uma definição clara de microcrédito, uma vez que o termo tem sido utilizado de diversas maneiras dentro da literatura disponível. Uma observação inicial importante é que microcrédito é parte integrante das microfinanças. Com base em Morduch (1999), Monzoni Neto (2006) e Righetti (2008), admite-se que as microfinanças dizem respeito ao acesso e ao uso de serviços financeiros por parte da população de baixa renda, geralmente excluída do sistema financeiro tradicional.

O microcrédito nada mais é do que o crédito concedido no âmbito das microfinanças, e, do ponto de vista da pesquisa aqui apresentada, o termo será definido como a concessão de empréstimos direcionados a atividades produtivas, ou seja, a microempreendimentos. A despeito da notoriedade do microcrédito, há outros serviços, no âmbito das microfinanças, com significativo potencial para aumentar o bem-estar da população mais pobre. Exemplo disso é o microsseguro, que nada mais é do que um mecanismo de proteção de ativos previamente acumulados. Enquanto o microcrédito tem como objetivo financiar atividades produtivas que propiciem acúmulo de ativos, o microsseguro busca assegurar a proteção e a manutenção de tais ativos diante de eventos adversos. Como analisado em Gonzalez, Piza e Garcia (2009), a sinergia entre os dois serviços é óbvia no que diz respeito ao combate à pobreza.

O conceito de microcrédito, tal como é hoje popularmente utilizado, surgiu nos anos 1970, a partir da adoção de um conjunto importante de inovações que buscavam viabilizar a 
oferta de crédito para os mais pobres. Portanto, seu surgimento não se liga a novas concepções teóricas ou acadêmicas, mas a uma "revolução concreta" na maneira de ofertar crédito de pequena monta para pessoas pobres, que vivem, geralmente, na informalidade. Os modelos tradicionais de negócio excluíam os mais pobres, por não apresentarem soluções inovadoras que mitigassem três grandes obstáculos: (a) alto risco; (b) custos de transação elevados; e (c) ausência de garantias.

Assim, como enfatizado por Aghion e Morduch (2010), os contornos da atual definição de microcrédito são dados exatamente pelas inovações que visam a superar as mencionadas barreiras: empréstimos em grupo, agentes de crédito, empréstimos progressivos, frequência de pagamentos e foco nas mulheres.

Uma inovação importante do microcrédito é o foco nas mulheres. É preferível conceder microcrédito às mulheres a oferecê-lo aos homens. Os principais argumentos para justificar essa assertiva referem-se à oposição ao viés sexista do sistema financeiro, em muitos mercados, e ao papel desempenhado pela mulher na família e na sociedade, o que contribui fortemente para a redução da pobreza.

Devido a diferentes aspectos culturais e às construções sociais de relação, é patente ainda hoje, se bem que menos que décadas atrás, a dificuldade das mulheres para acessar recursos materiais e financeiros. Quanto a isso, a principal desigualdade está no ingresso e nas condições do mercado de trabalho, mas a diferença de gênero no acesso a serviços financeiros também é expressivo. Na década de 1970, em Bangladesh, as mulheres representavam menos de $1 \%$ de todos os empréstimos. No Brasil, de acordo com Gonzalez et al. (2009), estima-se que $33 \%$ dos empreendimentos da economia informal urbana sejam liderados por mulheres. Ocorre que, dentre os mais de 10 milhões de empreendimentos desse segmento, somente $5 \%$ haviam tido acesso a crédito.

O segundo argumento refere-se ao conceito de empowerment das mulheres. Pode-se entendê-lo como o aumento da autonomia, da autoridade e da legitimidade das mulheres perante o lar e a sociedade, por se acreditar que elas possuem mais prudência na administração dos recursos do que os homens. Pesquisas demonstram diferenças estatisticamente significantes desse efeito, como melhoria na renda, decorrente do esforço das mulheres, tendo como resultado maior dispêndio com alimentação, saúde e educação dos filhos, além de crescimento de benfeitorias, como reforma e ampliação das moradias. Em resumo, crédito concedido a mulheres reverte em maiores benefícios ao conjunto dos membros de uma família.

Pensando em uma cadeia de impacto, o engajamento das mulheres traz mudanças sociais mais amplas. Pode-se relacioná-lo ao aumento do uso de métodos contraceptivos, o que pode se refletir em variações nos índices de fertilidade; evidências concretas existem de participação mais ampla das mulheres em associações comunitárias e maior participação política em geral. Observa-se, dessa forma, que o foco em mulheres representa uma redefinição do papel social da mulher: passa-se a enxergá-la, de acordo com Amartya Sen, Prêmio Nobel de economia, como dotada de uma livre condição de agente (com capacidade de agir) e promotora dinâmica de transformações sociais. 


\section{Capital social, recursos sociais, organizacionais}

Várias dimensões podem ser observadas para substituir a propriedade ou o capital em geral como forma de garantia dos empréstimos de microcrédito. Essas dimensões são, sucintamente, os recursos organizativos do local, o capital social e a solidariedade entre os membros da comunidade, e elas podem ser observadas por métodos qualitativos. Há, entretanto, uma expectativa de que sejam traduzidas em medidas quantitativas, para serem consideradas como equivalentes de quantidades de capital. Para as famílias socialmente vulneráveis, contudo, essas dimensões podem representar a chance de voltarem a ter algum valor de troca por seu trabalho e, com isso, sobreviverem à sociedade.

Os recursos organizativos são as possibilidades que a população tem de criar pequenos empreendimentos para gerar renda. São uma forma de troca econômica, chamada, por Peter Spink (2009), de nanoeconomia:

Independentemente de sua aparência, a nanoeconomia está longe de ser uma noção abstrata. É um produto social cujas possibilidades se expressam em materialidades e socialidades; uma intersecção sociotécnica em constante negociação (p. 231).

E completa:

Empreendimentos caseiros são uma parte da nanoeconomia, pois se utiliza o pouco espaço disponível no lar para gerar produtos e/ou vender produtos e serviços. A miniloja na esquina que vende os produtos necessários para o dia a dia para pessoas que não têm espaço para guardar ou que não têm geladeira; a loja improvisada a partir da garagem ou na porta de entrada da casa que vende roupa de segunda mão; serviços de reparos e de consertos de roupas e equipamentos. Todos frequentemente sem alvará, sem registro, mas construindo possibilidades econômicas de sobrevivência, a partir de sua utilidade no microlugar, no quarteirão, na comunidade (p. 231).

Esses recursos são formas criativas de buscar a sobrevivência por meio da utilização do trabalho que não é valorizado no mercado formal.

O conceito de capital social é muito utilizado e com diferentes parâmetros. Apesar de sua ampla utilização nos últimos anos, esse conceito é, antes de tudo, um constructo que incorporou uma série de usos e significados. A ideia de que a qualidade das relações sociais tem implicações importantes no bem-estar de indivíduos, comunidades e sociedades possui uma longa trajetória nas ciências sociais (Adler \& Kwon, 2000). Contudo, a ideia de que o capital social pode se tornar um recurso produtivo com fins específicos é relativamente recente. Os primeiros trabalhos de Coleman (1988) e de Putnam $(1993,2000)$ foram os responsáveis pela popularização dessa forma de interpretação do termo.

Aqui, são apresentadas duas perspectivas sobre capital social: a de Pierre Bourdieu, sociológico francês, e a de James Coleman. Bourdieu (2005) defende que seu conceito de capital social é diferente daquele do americano Coleman, pois, para ele, é uma forma de intercâmbio entre as trocas simbólicas e o simbolismo das forças econômicas. As formas de intercâmbio de símbolos dão-se dentro de um campo simbólico que apresenta diferenças a serviço da dominação de uns pelos outros. Bourdieu analisou as forças simbólicas em sociedades autorreguladas (sociedade Kabylia e Béarn) e em sociedades desreguladas (como a sociedade francesa atual). Nas sociedades ocidentais, a posse de objetivações das trocas simbólicas (como diplomas escolares) serve como forma de dominação sobre parcelas que não detêm essas objetivações:

A dominação já não tem necessidade de ser exercida de maneira direta e pessoal quando está implicada na posse dos meios (capital econômico e cultural) de se apropriar dos mecanismos de produção econômica e do campo da produção cultural que tendem a assegurar sua própria reprodução, através de seu próprio funcionamento e independentemente de toda intervenção 
intencional dos agentes. É, então, no grau de objetivação do capital social acumulado que reside o fundamento de todas as diferenças pertinentes entre os modos de dominação (Bourdieu, 2001, p. 193, itálico nosso).

As objetivações são as ações humanas produtivas de bens culturais ou econômicos. Assim, a posse de capital social é, do mesmo modo que a posse de capital econômico, um atributo desigual em uma sociedade capitalista. As ações de incremento da educação são uma forma de diminuir essa desigualdade, quando permitem uma socialização do capital social. No caso das famílias socialmente vulneráveis, seus membros que já detiverem certa qualidade de capital social podem ser auxiliados por medidas de apoio à produção, para transformarem esse capital social em capital econômico. Isso permite diferenciar as medidas quantitativas - por exemplo, a posse de diplomas - das medidas qualitativas, como o desempenho diante de tarefas produtivas que exigem capital social (por exemplo, a coordenação de atividades de pares em um empreendimento solidário).

Já Coleman (1988) entende o capital social como um insumo para a criação do capital humano que efetivamente age sobre a produção econômica. Capital social não é uma medida individualista, mas uma propriedade da rede de relações de certo ator social, ou seja, de um grupo social. Seu efeito é a facilidade de determinado ator produzir de acordo com condições de suas relações sociais. $\mathrm{O}$ capital social é determinado por qualidades da relação em rede do ator social. Essas qualidades são a obrigação, as expectativas e a confiança:

Caso A faça algo para B e confie que B retribuirá no futuro, isso estabelece uma expectativa em A e uma obrigação da parte de B. Essa obrigação pode ser compreendida com um crédito a receber de $\mathrm{A}$ sobre a ação de $\mathrm{B}$. Caso $\mathrm{A}$ tenha um grande número desses créditos com várias pessoas com quem tem relação, caracteriza-se uma relação análoga ao capital financeiro. (Coleman, 1988, p. 102, tradução dos autores)

Ou seja, a concepção de capital social de Coleman representa a possibilidade de uma pessoa transformar a confiança e a reciprocidade da sua rede de relacionamentos em capital financeiro.

Várias formas mais instrumentais de representar essa dimensão do capital social das redes sociais foram desenvolvidas, dentre as quais as medidas do Banco Mundial e da Organização para a Cooperação e Desenvolvimento Econômico (OCDE) são as mais conhecidas. $\mathrm{O}$ instrumento do Banco Mundial mede o capital social como parte de um sistema social e, deste modo, apresenta entradas (inputs) e resultados (outputs). Composição, forma e cooperação na rede social constituem a entrada do sistema capital social. Confiança nas instituições locais e adesão a normas sociais são, ao mesmo tempo, entradas e resultados do sistema. E o resultado, por fim, é a composição das ações coletivas (Franke, 2005). Já a OCDE utiliza indicadores da coesão social que são passíveis de serem medidos: participação social, apoio social, redes sociais e participação civil (Franke, 2005).

Cabe, aqui, uma advertência sobre a tensão entre a medida e o aspecto multifacetado do fenômeno do capital social e dos recursos locais: a necessidade de medir e representar a dinâmica dos vínculos e relações sociais produz medidas para reduzir o fenômeno a dimensões operacionais. Contudo, a dinâmica implícita do fenômeno social, do qual deriva o conceito de capital e desenvolvimento local social, força, constantemente, a se voltar à observação qualitativa do fenômeno, para não perdê-lo de vista. 


\section{Método}

O método desta pesquisa é plural, pois abrigou diferentes saberes, como a gestão pública, a psicologia social e as finanças. A relação entre os pesquisadores e os pesquisados foi mediada por uma pesquisa-ação realizada na comunidade por um dos pesquisadores. Essa pesquisa-ação parte de princípios da psicologia social comunitária (Freitas, 2000), ou seja, procura uma relação de respeito com as demandas da comunidade e busca condições para que a comunidade seja autora de suas transformações sociais. A intenção é estabelecer uma relação que facilite sua capacidade de engajamento, para enfrentar a opressão social, na linha da Pedagogia do Oprimido, de Paulo Freire (2008). Quando a pesquisa começou, foram estabelecidos diálogos com lideranças locais e agentes públicos de proteção social, em lugar de se impor o interesse dos pesquisadores sobre a demanda dos moradores da comunidade. Além disso, estabeleceu-se um acordo, segundo o qual não só haveria feedback de seus resultados como também seria promovida alguma intervenção na comunidade.

A pesquisa foi dividida em três etapas: grupos de discussão, entrevistas com questionários fechados e entrevistas semidirigidas. Ao mesmo tempo, foram continuamente pensadas as possibilidades de feedback e de intervenções na comunidade.

Para a definição do questionário a ser utilizado na pesquisa, realizou-se, primeiramente, um levantamento sobre as metodologias já existentes para a mensuração de capital social. Analisando o extenso material publicado sobre o assunto, concluiu-se que uma publicação do Banco Mundial (Grootaert et al., 2003) seria um bom referencial, tanto por considerar, em suas questões, a natureza multidimensional do conceito de capital social ${ }^{4}$ como por ter como foco, para sua aplicação, os países em desenvolvimento.

O questionário original apresenta 95 questões, que englobam seis dimensões: grupos e redes; confiança e solidariedade; ação coletiva e cooperação; informação e comunicação, coesão social e inclusão; empowerment e ação política. No anexo B da publicação, há uma versão mais curta do questionário, com as mesmas seis dimensões, mas em apenas 27 questões. Devido ao tempo necessário para a aplicação de cada questionário, optou-se por utilizar como base essa versão sintética.

As 27 questões foram traduzidas e adaptadas tanto à realidade brasileira como à da Vila Nova Jaguaré. Foram acrescentadas perguntas sobre a situação familiar, para identificação das pessoas e/ou familiares que residem no mesmo local dos entrevistados; sobre o recebimento de auxílios e benefícios sociais; a renda familiar mensal; se alguém na família possui conta bancária ou nome sujo; e a existência de coleta de esgoto no domicílio. Ao final do questionário, incluíram-se questões sobre o sentimento de desrespeito ou discriminação e a confiança nos serviços públicos. Com o objetivo de facilitar a tabulação das respostas, algumas questões - que no questionário original se desdobravam em a, b, c - foram consideradas independentes. Essas modificações resultaram no questionário de 44 perguntas que foi utilizado na pesquisa.

Adicionalmente, foi elaborado um termo de consentimento livre e esclarecido, apresentado aos entrevistados antes da aplicação do questionário, informando sobre a pesquisa, garantindo o acesso aos responsáveis, a desistência e o direito a confidencialidade. Foram aplicados 60 questionários durante o mês de setembro de 2010. Para tanto, contou-se com a colaboração das agentes de proteção social do Programa Ação Família (PAF), que acompanharam os pesquisadores até a residência dos entrevistados. Em um segundo momento, durante a 5ํㅗ Mostra Cultural da Congregação de Santa Cruz e III Ação Cidadania do Programa Ação Família - realizada nos dias 5 e 6 de novembro -, teve-se a oportunidade de aplicar os mesmos questionários a mais 15 pessoas, moradoras do bairro, mas não participantes do PAF.

4 Dado que o capital social é frequentemente definido em termos de grupos, redes, normas e confiança que as pessoas têm disponíveis para propósitos produtivos. 
Dessa forma, pôde-se realizar uma comparação entre dois grupos de pessoas da mesma comunidade, mas com uma característica distintiva: participam ou não participam do PAF.

A partir dos resultados dos questionários, foram realizadas cinco entrevistas em profundidade com moradores que se destacaram por suas respostas em duas dimensões: vontade de estabelecer ou não negócio próprio, alto e baixo escores no questionário de capital social.

\section{Resultados e análises}

\section{Grupos pesquisados}

Foram aplicados 75 questionários na comunidade Nova Jaguaré, sendo 60 respondidos por participantes do PAF, doravante denominado grupo participante. Os outros 15 questionários foram aplicados a pessoas que não participam do PAF, que será chamado de não participante. As diferenças encontradas entre os dois grupos permitem apenas que se aventem hipóteses a serem exploradas em pesquisas futuras. A seguir, serão apresentados pontos em que os dois grupos foram destoantes.

O primeiro ponto que merece destaque é que 6 respondentes, dentre os 15 não participantes, afirmaram não participar de nenhum grupo, o que corresponde a $40 \%$ do referido grupo. Dos 9 respondentes restantes, 8 afirmaram participar de um único grupo: a igreja. No grupo pesquisado, 48,33\% (29 respondentes) participam de dois grupos (o PAF e a igreja). Esses dados indicaram a importância potencial das igrejas - notadamente de linhagem neopentecostal - na aglutinação das redes sociais no interior da região estudada.

O grupo não participante possui maior renda média mensal: $\mathrm{R} \$ 1.682,86$, contra $\mathrm{R} \$$ 950,00 do grupo participante. Chamou a atenção o fato de 4 não participantes (26,7\%) afirmarem não participar de nenhum programa de transferência de renda. Adicionalmente, 2 pessoas $(13,3 \%)$ afirmaram não ter coleta de esgoto em seus domicílios. No grupo participante, 29 respondentes (48,3\%) afirmaram não ter coleta de esgoto, e 33 respondentes (55\%) declararam receber algum tipo de benefício social (participação em programas de transferência de renda, aposentadoria e pensão) ou receber cesta básica de instituições filantrópicas, como a própria igreja. Esses dados parecem indicar que os participantes do PAF vivem em condições de maior vulnerabilidade do que os não participantes. É importante mencionar que o potencial de comparação entre os dois grupos é restrito, uma vez que a participação no PAF deixa de ser a única variável de diferenciação, sendo acompanhada de distinções no perfil socioeconômico.

A comparação entre os grupos fez emergir a necessidade de distinguir entre estoque de capital social e sua efetiva utilização. Considerando o grupo participante, $76,7 \%$ (46 respondentes) dos entrevistados afirmaram não achar as pessoas confiáveis, percentual maior do que os $66,7 \%$ (10 respondentes) do grupo não participante. Uma primeira leitura permite a hipótese de que há falta de confiança - importante elemento do capital social - entre os membros do grupo participante. No entanto, $45,8 \%$ das respostas válidas nesse mesmo grupo (27 respondentes) indicam que os vizinhos provável ou definitivamente emprestariam a quantia necessária à sobrevivência do respondente no período de uma semana. Curiosamente, no grupo não participante, foi menor a proporção de pessoas que não consideram confiáveis as demais: apenas 26,6\% (4 respondentes) afirmaram que os vizinhos os ajudariam.

Quando perguntados se os vizinhos estão dispostos a ajudar em caso de necessidade, 56,7\% (34 respondentes) dos participantes do grupo participante manifestaram respostas 
positivas ("Provavelmente, sim" ou "Definitivamente, sim"). Entre os não participantes, o percentual correspondente é um pouco menor: $53,4 \%$ (8 respondentes).

A mesma tendência é encontrada quando aos membros dos dois grupos foi feita a pergunta: "Na comunidade, você precisa estar atento ou alguém poderá se aproveitar?". 68,3\% dos respondentes do grupo participante (41 pessoas) afirmaram que ficam atentos com algumas pessoas (40\%, 24 respondentes) ou nunca se preocupam em ficar atentos (28,3\%, 17 respondentes). É importante mencionar que as outras duas opções de resposta eram: "Sempre fico atento" e "Fico atento com a maioria das pessoas". Esta foi, no grupo não participante, a resposta de 53,3\% (8 respondentes), e aquela ("Sempre fico atento"), a de $40 \%$ (6 respondentes).

No grupo participante, $96,7 \%$ (58 pessoas) afirmaram contribuir com dinheiro ou com tempo em alguma obra ou projeto cujos fins sejam coletivos. Já no grupo não participante, $53,3 \%$ ( 8 respondentes) contribuiriam com dinheiro e $86,7 \%$ (13 respondentes) com tempo.

Nas entrevistas dirigidas, com questionário, as respostas indicam crença na capacidade de mudar a própria vida (média 4, em escala de 1 a 5). Mas as respostas sobre mudanças na comunidade são opostas. Há grande descrença quanto a poderem mudar a própria comunidade. Quando perguntados se haviam participado de alguma atividade de reivindicação para a comunidade, $81 \%$ disseram que não.

\section{O microcrédito na realidade da Jaguaré}

Tendo em vista a discussão anterior, o material empírico coletado por meio de questionários, entrevistas e grupos de discussão foi analisado, tomando-se como fio condutor a verificação da efetiva materialidade e a importância das inovações típicas do microcrédito, em meio à realidade atual da comunidade. Além disso, buscou-se avaliar o potencial de tais inovações, ou seja, como estas podem ser utilizadas para transformar a realidade da comunidade. Nos resultados, foi destacada a discussão do acesso ao crédito.

\section{Mecanismos de acesso a crédito}

Conforme inúmeras evidências presentes na literatura sobre microfinanças, tais como Aghion e Morduch (2010) e Collins, Morduch, Rutherford e Ruthven (2009), a população mais pobre, geralmente excluída do sistema financeiro tradicional, acaba desenvolvendo formas de sobrevivência que incluem mecanismos informais de acesso a serviços financeiros, notadamente crédito e poupança. Collins et al. (2009), em trabalho etnográfico realizado em Bangladesh, África do Sul e Índia, mencionam diferentes mecanismos financeiros informais que acabam por fazer parte do cotidiano das comunidades alienadas do sistema financeiro formal, tais como dinheiro guardado em casa, na casa de amigos, empréstimos tomados de amigos e cadernetas em pequenas lojas.

Cumpre lembrar que tais mecanismos são, repetidas vezes, originados e reproduzidos a partir de laços e relacionamentos que acabam por constituir o estoque de capital social das respectivas comunidades. Não obstante o benefício potencial, questiona-se, sobretudo, a eficiência de alguns desses mecanismos, como, por exemplo, taxas excessivas de juros em empréstimos, ou, ainda, retornos negativos em poupanças informais.

O material empírico coletado no Jaguaré evidencia que as necessidades de crédito são atendidas, preponderantemente, por (a) agiotas; (b) amigos e vizinhos diretamente; e (c) empréstimos indiretos, de amigos e vizinhos. Sobre os agiotas, os relatos da Jaguaré se assemelham àqueles de Collins et al. (2009). O cumprimento das obrigações associadas aos empréstimos dá-se por meio da coerção e da violência, como evidenciado pela frase "se não 
pagar", dita em um dos grupos de discussão e seguida por acenos e risos de concordância por parte do grupo. Outro aspecto interessante relaciona-se ao interesse dos agiotas em manter o grau de dependência das pessoas da comunidade. Essa parece ser a estratégia utilizada para manutenção dos ganhos financeiros. É expressiva dessa situação a frase ouvida: "Ele empresta um dinheiro para você, e todo mês você paga uma quantia, e não o que você pegou".

A menção a recorrer a amigos e parentes teve grande destaque nas entrevistas e nos grupos de discussão. Alguns exemplos são frases como: "a gente procura ajudar as pessoas", "tem vizinhos meus que são certos, e outros, não", "só empresto para família", "até quando alguém morre, se passam pedindo ajuda, a gente ajuda".

Sobre empréstimos indiretos valendo-se de vizinhos e parentes, ainda que em menor frequência, há evidências de que esse recurso está presente na Jaguaré. Aliás, tal fator não causa surpresa, diante da forte expansão do crédito no Brasil, em especial o crédito para pessoa física. De acordo com o Banco Central do Brasil (2010), o volume de crédito representava cerca de 27\% do PIB em 2004, observando-se que a porcentagem estimada para 2010 passou para $47 \%$ do PIB. Ou seja, espera-se que haja mais acesso ao crédito, mesmo para segmentos mais pobres da população. Além disso, a possibilidade de recorrer a vizinhos e parentes acaba por engendrar certo efeito multiplicador, isto é, o maior "acesso" a crédito de alguns possibilita o "uso" por um número de pessoas potencialmente maior.

Uma das consequências do contexto acima é a inscrição crescente de pessoas da comunidade nas centrais de informação de crédito, tais como Serasa e SCPC. O termo nome "sujo" apareceu com relativa frequência e, geralmente, associado a ter "emprestado o nome" para alguém. Exemplos disso são as frases: "Pessoa com nome sujo não consegue empréstimo, não"; "Fiquei com nome sujo por conta de emprestar para os outros [cunhada]"; "Enquanto ele [irmão] paga direitinho, eu faço pra ele; a hora que ele pisar na bola, não faço mais".

A manutenção do nome "limpo" tem significados importantes na luta por reconhecimento, pois se considera, culturalmente, que o nome de uma pessoa é parte de seus atributos de identidade. Assim, também nas trocas econômicas, para várias das pessoas que participaram dos grupos de discussão, constitui um bem importante, já que a maioria não tem moradia juridicamente reconhecida ou outros bens, a não ser o nome "limpo" na praça. As relações dentro da favela tampouco são passíveis de mediação por um recurso ao direito, quer por seu custo, quer porque muitas transações são informais. Há, inclusive, relações de locador e locatária em casas e cômodos na favela cujo contrato se dá "pelo fio do bigode", como disse um morador.

Essa importância do nome foi discutida quando os moradores se referiram aos problemas que vivem quando têm o nome "sujo". A carga emocional de vergonha e humilhação associada ao termo foi, manifestamente, muito grande.

Apesar do relevo dessa colocação, notou-se, contudo, certa contradição nos relatos de vários moradores que afirmaram emprestar seu nome. Essa atitude mostra outra dimensão de confiança e trocas, que não são as formais. É comum que um parente ou amigo peça o empréstimo do nome e do CPF para uma compra a crédito. Pode-se, assim, admitir que a negação de um pedido desse tipo implica estremecimento do vínculo de solidariedade entre os envolvidos.

Não foi possível notar diferença entre as pessoas de acordo com seu escore no questionário sobre o capital social. Os entrevistados indicaram problemas e soluções similares para lidar com o crédito. Essa situação parece indicar que a medida do capital social não é uma dimensão individual, e sim uma característica coletiva. 


\section{Formação de grupos solidários}

Após análise das três etapas da pesquisa (grupo de discussão, questionário e entrevista semidirigida), foi possível perceber algumas barreiras para obter a adesão dos moradores a grupos, o que pode dificultar a obtenção de microcrédito, uma vez que o modelo de empréstimos em grupo tem sido largamente utilizado pelas instituições. Quando questionados a respeito da vizinhança em relação à contribuição para o desenvolvimento de um empreendimento, uma moradora da região assegurou não receber ajuda quanto a atividades produtivas: "Não tive ajuda. Fiz geladinho pra vender..., pelo contrário, [o vizinho] virou um concorrente".

A partir dessa afirmação, teve início uma discussão a respeito da concorrência na vizinhança, e outra moradora argumentou ser importante tal concorrência para incentivar uma produção de melhor qualidade e que a imitação do produto que a vizinha vendia só reforçava a viabilidade de sua ideia. No decorrer da discussão, pôde-se notar que cresceu, entre os envolvidos, a percepção de que era melhor ter os vizinhos como parceiros do que como ameaças.

Os dados coletados com a aplicação do questionário demonstraram que, em relação a confiança e solidariedade, $66,7 \%$ dos entrevistados acreditavam que, de modo geral, as pessoas não são confiáveis, e 40\% afirmaram estar sempre atentos dentro da comunidade, para outros moradores não tirarem proveito. Apesar desses valores altos, ao comparar o grupo de controle com membros do PAF entre o grupo pesquisado, estes apresentam maior coesão e adesão a grupos. A média de grupos a que a família pertence passa de um para dois, enquanto $40 \%$ do grupo de controle não pertence a nenhum grupo; apenas $5 \%$ do grupo pesquisado não soube apontar algum grupo. Com base nessa análise, pode-se perceber que os moradores da região estudada têm potencial para formar grupos aptos a participar do desenvolvimento produtivo.

Ao entrevistar uma moradora que produz artesanalmente pães de mel, notou-se que, em sua visão, a maneira de expandir o empreendimento seria aumentar a quantidade de vendas. Vale ressaltar que se trata de pessoa que, apesar de manifestar a desconfiança que tem em colocar seu produto para ser revendido - por ter sofrido calotes de outros moradores -, afirma contar com as irmãs e algumas outras pessoas para fazer a revenda em outros pontos. Da mesma maneira, o desconforto em formar parceria foi expresso por outros moradores, que se sentem mais seguros agindo individualmente.

Cabe salientar, ainda, a importância dos trabalhos das instituições de microcrédito atuando na região de Nova Jaguaré, já que seria necessário empreender um trabalho de conscientização entre os moradores para fomentar a união e, dessa maneira, facilitar a concessão de crédito que venha contribuir para o desenvolvimento do local. A formação de grupos não seria imposta pelos agentes de créditos, que agiriam para informar sobre a importância da coesão do grupo e o bom relacionamento entre seus integrantes.

\section{Análise das relações intersubjetivas na economia e no pertencimento à comunidade}

No conteúdo das entrevistas, duas características foram marcantes: as mudanças nos laços de solidariedade ao longo do tempo e a diminuição da expectativa de modificar coletivamente a realidade da comunidade, o que mostra uma degradação da luta por reconhecimento e um aumento da mediação das relações pelo capital, o que não acarreta uma suficiente generalização do outro.

Uma jovem de 26 anos, com uma filha de 8 anos, disse que sua expectativa para melhorar de vida era "Conseguir um trabalho num lugar assim, uma multinacional, uma empresa grande que eu tenha condições de crescer, porque deve ter empresa boa, mas eu não tenho pra onde ir assim, né?". Acrescentou que tinha que brigar com colegas para, às vezes, 
levar a filha para o curso técnico, pois não tinha com quem deixá-la. Dizia, ainda, sentir-se penalizada por a filha lhe pedir um quarto, uma vez que, com o que ganha, pode viver em apenas um cômodo. Quando perguntada se sentia capaz de mudar a comunidade, ela respondeu que não e, depois, discorreu sobre o problema do vício e do tráfico de drogas e não deu indícios de que seria capaz de participar de uma mudança coletiva que diminuísse o trafico.

Outra moradora conta que sua decisão por deixar o emprego formal e passar a vender pão de mel foi motivada pelo medo de que o filho se envolvesse com "más companhias", porque, quando tinha 10 anos, o filho começou a andar com colegas que podiam, na sua avaliação, "levá-lo para o crime". Relata que deixou, então, o trabalho e passou a produzir doces em casa, para estar mais perto do filho, que passou dificuldades recentemente, com o nascimento de uma filha, o que limitou sua capacidade de vender de porta em porta na comunidade. Apesar das dificuldades, entretanto, afirma que valeu a pena, que colegas do filho foram, recentemente, levados pela polícia para averiguações. Declara ter orgulho de ter comprado um carro e, conforme sublinhou, sem ajuda de qualquer companheiro, pois "homem só atrapalha".

Uma senhora de 70 anos de idade, moradora do bairro há 40 anos, disse que via muitas mudanças na vizinhança. Comenta que a principal é que, atualmente, as pessoas só se ajudavam se houvesse algum pagamento:

Não, o meu genro trabalha de pedreiro, e ele falou: "Ó, dona F., vê se você pode comprar o material, que aí eu faço". Aí tem que pagar pra ele, que ele não vai também trabalhar de graça, que ele precisa comer e fazer as coisas também dele, né? Mas aí ele faz por menos, ele não nega pra mim, que tudo que eu vou fazer aqui em casa ele que faz pra mim, né?

Esta senhora mostra facilidade de manter e estabelecer vínculos; por exemplo, com antigos moradores e com o ex-empregador e funcionários da empresa em que trabalhou como faxineira.

Essas mudanças nos vínculos e a dificuldade em se representar como uma agente de transformação indicam que as relações de reconhecimento recíproco, quando mediadas pelo capital, não fortalecem a solidariedade. Por outro lado, a expectativa por mudanças na própria vida tem o potencial de formar, nas práticas sociais, novas demandas de reconhecimento. $\mathrm{O}$ mais forte exemplo disso é a luta por reconhecimento das mulheres entrevistadas. Elas buscam um reconhecimento recíproco, que pode chegar à solidariedade. Isso aparece nas declarações, desde a jovem que quer ter direito de estudar e cuidar da filha sem depender da família ou de um companheiro até a vendedora de doces.

Por último, durante os dois dias da a 5ª Mostra Cultural da Congregação de Santa Cruz e III Ação Cidadania do Programa Ação Família, a equipe da pesquisa desenvolveu uma ação explicativa sobre o uso do crédito e a recuperação do "nome limpo" para a comunidade. O trabalho foi realizado na própria comunidade, a partir dos diálogos iniciais com suas lideranças, que previam um retorno ao coletivo a partir dos resultados da pesquisa.

\section{Considerações finais}

Em um contexto no qual parcela significativa da população mundial vive em condições de elevada vulnerabilidade social, o microcrédito tem o potencial de desempenhar o papel de elemento promotor do desenvolvimento social e redutor da pobreza. Entretanto, é preciso observar que a subjetividade das pessoas submetidas a longos períodos de vulnerabilidade social sofre consequências que diminuem a possibilidade de que o potencial do microcrédito se materialize. A capacidade de produzir, por meio do acesso a recursos de crédito, pressupõe que 
as pessoas têm que voltar a acreditar também em si, superando o silêncio, e procurar ações produtivas, superando condutas meramente reativas.

Além disso, o que se define atualmente como microcrédito resulta de um conjunto de inovações, dentre as quais se destaca a garantia solidária, obtida pelos empréstimos em grupo. A viabilidade de tais arranjos relaciona-se ao estoque de capital social existente, o qual, por sua vez, se insere no contexto histórico e social das comunidades. Não obstante, há espaço para execução de políticas públicas e para atuação de instituições privadas, de forma a organizar recursos preexistentes capazes de promover a melhoria das condições produtivas.

As preocupações com o "nome sujo" indicam a complexidade das relações entre a prática social e a economia. Por um lado, o conceito de capital social indica a importância das relações de solidariedade e dos laços fracos. Mas essas mesmas relações geram pressões de parentes ou conhecidos para o "empréstimo" do nome para compras parceladas.

A fraca crença na capacidade de mudar a vida da comunidade, em oposição à forte crença de que podem mudar a própria vida, indica outra contradição entre a compreensão do capital social e a da luta por reconhecimento. No modelo do capital social, quanto mais fortes são os vínculos, mais efetivas são as chances de haver investimentos de tempo e recursos na dimensão coletiva. Mas as respostas não mostram esse engajamento.

Novos estudos poderão caminhar, por exemplo, na linha de quantificação de capital social e relação com os arranjos de crédito, formais e informais. Isso envolveria, naturalmente, novas idas a campo, a fim de verificar as relações entre capital social e microcrédito ao longo do tempo. Outra linha de continuidade se caracterizaria pela aplicação da metodologia desta pesquisa em outras comunidades, o que permitiria um estudo qualitativo cross-case.

\section{Referências}

Adler, P. \& Kwon, S. W. (2002). Social capital: prospects for a new concept. Academy of Management Review, 27 (1), $17-40$.

Aghion, B. A. \& Morduch, J. (2010) The economics of microfinance. Cambridge: The MIT Press.

Banco Central do Brasil. (2010). Relatório de inclusão financeira (nº 1). Brasília. Recuperado em junho, 2011, de http://www.bcb.gov.br/Nor/relincfin/relatorio_inclusao_financeira.pdf.

Bourdieu, P. (2001) A produção da crença: contribuição para uma economia dos bens simbólicos. São Paulo: Zouk.

Castel, P. (1997). A dinâmica do processo de marginalização: da vulnerabilidade a desfiliação. Cadernos CRH, Salvador, 26, 19-40.

Coleman, J. S. (1988). Social capital in the creation of human capital. The American Journal of Sociology, 94, Supplement: Organizations and Institutions: Sociological and Economic Approaches to the Analysis of Social Structure, S95-S120.

Collins, D., Morduch, J., Rutherford, S. \& Ruthven, O. (2009). Portfolios of the poor: how the world's poor live on two dollars a day. Princeton: Princeton University Press.

Franke, S. (2005). Measurement of social capital reference document for public policy research, fevelopment, and evaluation. Canada: PRI Project.

Freire, P. (2008). Pedagogia do oprimido. São Paulo: Paz e Terra.

Freitas, M. F. Q. (2000). Psicologia na comunidade, psicologia da comunidade e psicologia (social) comunitária. In R. H. F. Campos (Org.), Psicologia social comunitária: da solidariedade à autonomia (pp. 54-80). Petrópolis: Vozes.

Gonzalez, L., Piza, C. T. \& Garcia, D. B. (2009). Sinergia entre microsseguro e microcrédito e o crescimento dos mercados no Brasil. Revista Brasileira de Risco e Seguro, Rio de Janeiro, 5 (10), 45-84.

Grootaert, C., et al. (2003). Measuring social capital: an integrated questionnaire. World Bank Working Paper, no 18. Washington: Banco Mundial.

Honneth, A. (2003). Luta por reconhecimento: a gramática moral dos conflitos sociais (L. Repa, trad.). São Paulo: Editora 34 .

Horkheimer, M. \& Adorno, T. (1978). Temas básicos de sociologia. São Paulo: Cultrix.

Kowarick, L. (2009). Viver em risco. São Paulo: Editora 34. 
Monzoni Neto, M. P. (2006). Impacto em renda do microcrédito: uma investigação empírica sobre geração de renda do crédito popular solidário (São Paulo Confia), no município de São Paulo. Tese de Doutorado, Fundação Getulio Vargas, Escola de Administração de Empresas de São Paulo, São Paulo.

Morduch, J. (1999). The microfinance promise. Journal of Economic Literature, 37 (4), 1569-1614.

Prefeitura Municipal de São Paulo. Urbanização da Favela Vila Nova Jaguaré. Recuperado em 30 de novembro, 2008, de http://www6.prefeitura.sp.gov.br/noticias/sec/habitacao/2008/06/0001.

Putnam, R. D. (1993). The prosperous community: social capital and public life. American Prospect, 13, 35-42.

Putnam, R. D. (2000). Social capital: measurement and consequences. Trabalho apresentado em International Symposium on the Contribution of Human and Social Capital to Sustained Economic Growth and WellBeing. Quebec: Human Resources Development Canada and OECD, 19 a 21 de março, 2000.

Righetti, C. C. B. (2008). Efeitos do microcrédito na geração de renda em microempreendimentos: avaliação de impacto do programa Real Microcrédito. Tese de Doutorado, Fundação Getúlio Vargas, Escola de Administração de Empresas de São Paulo, São Paulo.

SEADE. (2008). Índice Paulista de Vulnerabilidade Social. Recuperado em outubro, 2008, de http://www.seade.gov.br/produtos/ipvs/apresentacao.php.

SMADS. Secretária Municipal de Assistência e Desenvolvimento Social de São Paulo. (2006). Ação família: viver em comunidade. Recuperado em outubro, 2008, de http://portal.prefeitura.sp.gov.br/secretarias/ assistencia_social.

Spink, P. (2009). Microcadeias produtivas e a nanoeconomia: repensando o trabalho decente. Cadernos de Psicologia Social do Trabalho, 12 (2), 227-241.

\section{Endereço para correspondência}

luisgaleao@usp.br, lauro.gonzalez@fgv.br, mario.alves@fgv.br 